\title{
CLINICAL FEATURES OF 312 PATIENTS WITH JUVENILE IDIOPATHIC ARTHRITIS (JIA) SEEN IN A REFERENCE HOSPITAL IN 30 YEARS
}

Ana Laura Volpi Martins ${ }^{1, \star}$, Luciana Martins Carvalho ${ }^{1}$, Virgínia Paes Leme Ferriani ${ }^{1}$

1.Universidade de São Paulo, Ribeirão Preto (SP), Brazil.

*Corresponding author: ana.laura.martins@usp.br

\section{BACKGROUND}

Juvenile idiopathic arthritis (JIA) is the childhood most common chronic rheumatic disease. The scarcity of data regarding this condition in the Brazilian population upholds the importance of clinical studies on the topic. We aimed to evaluate the clinical features of patients with JIA seen at a reference hospital.

\section{MATERIALS AND METHODS}

A retrospective study of medical chart revision from 01/01/1988 to 31/12/2017, selected by CID 10: M08.0 and categorized in the REDCap software. Inclusion criteria: more than 2 medical consultations in the immunology or rheumatology clinics (adult or pediatric) and JIA as the final diagnosis. Exclusion criteria: pathologies superposition. Deadline for follow up analysis was 21/09/2018. The categorical variables were expressed as absolute frequencies measurements and the numerical ones as means. Study approved by Institution's Ethics Committee.

\section{RESULTS}

CID 10 M08.0 was found in 540 charts and 312 (57.7\%) were included. Causes of exclusion were inconclusive diagnosis (23.2\%), another diagnosis (57.5\%): collagenous-vascular (37.4\%), infectious (32.1\%), orthopedic (12.2\%), genetic (10.7\%), tumoral (4.6\%) and inflammatory gastrointestinal (3.1\%) diseases, or incomplete follow-up (19.3\%). Included patients came from 109 cities, 64 (20.5\%) from Ribeirão Preto (SP), 208 (66.6\%) from 83 other cities in the state of São Paulo and 40 (12.8\%) from other states, including AM, MG, MT, MS, PR e RS. First symptom mean age was 6.6 years-old ( $S D=4.5)$ (Fig. 1). Onset categories were distributed as: oligoarticular (35.6\%), polyarticular rheumatoid factor (RF) negative (27.2\%), systemic (17.3\%), polyarticular RF positive (9\%), enthesis-related (9.3\%), undifferentiated (1\%) and psoriatic (0.6\%). Female were predominant in oligoarticular (66.7\%), polyarticular RF negative $(81.2 \%)$ and polyarticular RF positive (89.3\%) types, while male were predominant in systemic (68.5\%), enthesis-related (62.1\%) and undifferentiated (100\%) types (Fig. 2). Antinuclear factor (ANF) was positive in 104 patients (33.3\%), mainly in oligoarticular (51\%)

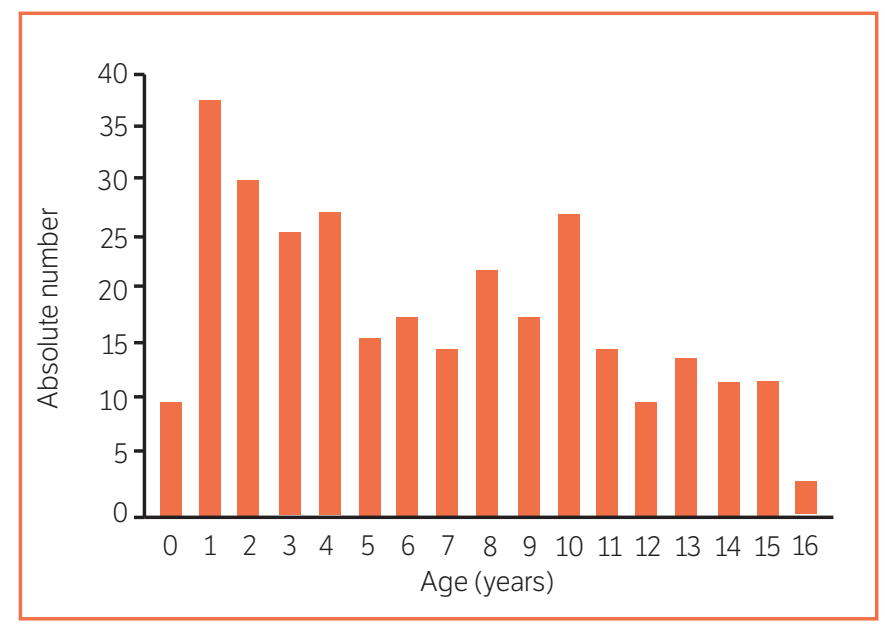

Figure 1. Distribution as to the onset age. 
and polyarticular RF negative (30.8\%). Anti-CCP was positive in 17 patients (5.4\%): 70.6\% in polyarticular RF positive and 17.6\% in the oligoarticular type. Additionally, 13 of the anti-CCP positive patients also had RF positive. HLA-B27 was found in 21 patients (6.7\%), $76.2 \%$ in enthesis-related type. As to the follow-up, $19 \%$ were referred to adult rheumatology, as they were over 18 years, $20,1 \%$ lost to follow-up and $0.4 \%$ died (macrophage activation syndrome).

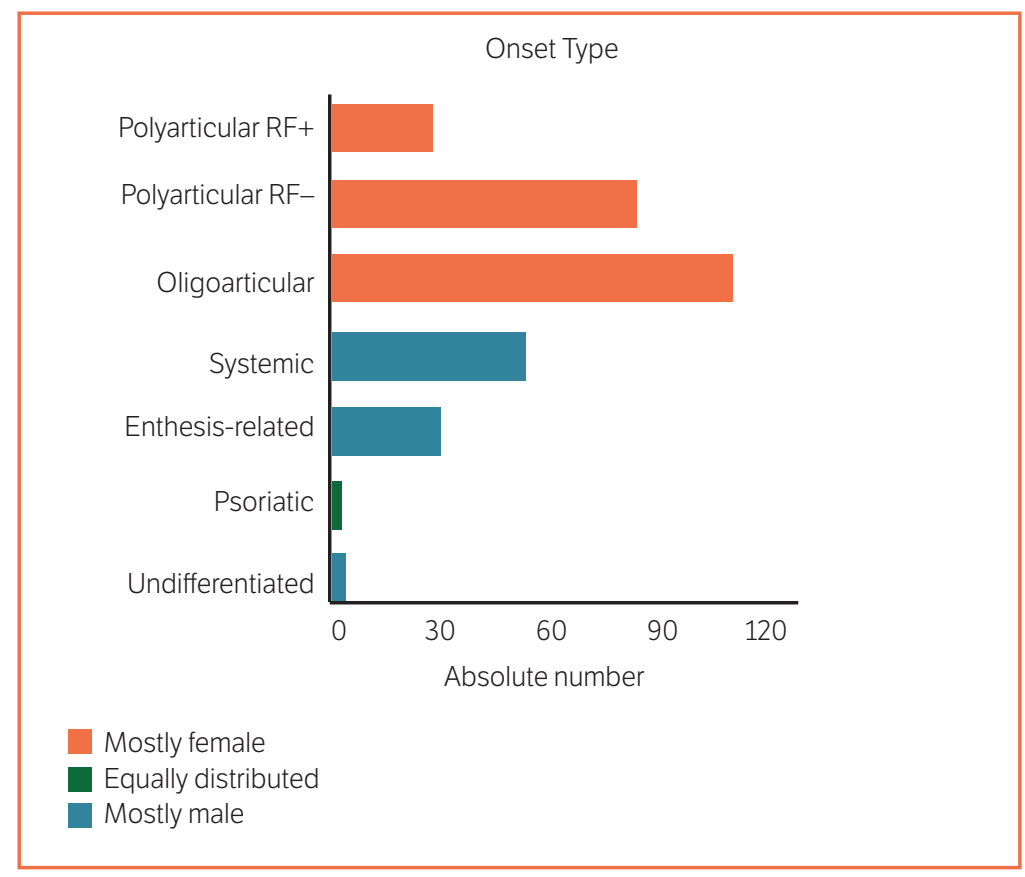

Figure 2. Distribution as to the onset type.

\section{CONCLUSION}

The clinical characteristics of this group of patients correspond with literature data. Patients came from many cities, including other states. This highlights the need of spreading knowledge about JIA, aiming to its early identification and prompt treatment. 